\title{
Patterns of endoscopy during COVID-19 pandemic: a global survey of interventional inflammatory bowel disease practice
}

\author{
Yan Chen ${ }^{1 *}$, Qiao $\mathrm{Yu}^{1 *}$, Francis A. Farraye ${ }^{2}$, Gursimran S. Kochhar ${ }^{3}$, Charles N. Bernstein ${ }^{4}$, Udayakumar Navaneethan $^{5}$, \\ Kaicun $\mathrm{Wu}^{6}$, Jie Zhong ${ }^{7}$, David A. Schwartz ${ }^{8}$, Hao Wu ${ }^{9}$, Jing-Jing Zheng ${ }^{10}$, Marietta Iacucci ${ }^{11}$, Ravi P. Kiran ${ }^{12}$, Bo Shen ${ }^{13}$ \\ ${ }^{1}$ Center for Infllammatory Bowel Diseases, Department of Gastroenterology, The 2nd Affiliated Hospital, School of Medicine, Zhejiang University, \\ Hangzhou, China; ${ }^{2}$ Department Gastroenterology and Hepatology, Mayo Clinic Florida, Jacksonville, FL; ${ }^{3}$ Department of Gastroenterology, \\ Allegheny General Hospital, Pittsburgh, PA, USA; ${ }^{4}$ Section of Gastroenterology, University of Manitoba IBD Clinical and Research Center, \\ Winnepeg, MB, Canada, ${ }^{5}$ Center for Advanced Endoscopy, Florida Hospital, Orlando, FL, USA; ${ }^{6}$ Department of Gastroenterology, Xijin Hospital, \\ The Fourth Military Medical University, Xi'an; ${ }^{7}$ Department of Gastroenterology, Ruijin Hospital of Shanghai Jiaotong University, Shanghai, \\ China; ${ }^{8}$ Department of Gastroenterology, Vanderbilt University Medical Center, Nashville, TN, USA; ${ }^{9}$ Department of Gastroenterology, Zhongshan \\ Hospital of Fudan University, Shanghai; ${ }^{10}$ The China Crohn's and Colitis Foundation, Hangzhou, China ${ }^{11}$ Institute of Translational Medicine, \\ Institute of immunology and immunotherapy and NIHR Biomedical Research Centre, University of Birmingham and University Hospitals \\ Birmingham NHS Foundation Trust, Birmingham, UK; ${ }^{12}$ Division of Colorectal Surgery and ${ }^{13}$ Center for Inflammatory Bowel Disease, Columbia \\ University Irving Medical Center, New York-Presbyterian Hospital, New York, NY, USA
}

Background/Aims: Performance of diagnostic or therapeutic endoscopic procedures in inflammatory bowel disease (IBD) patients can be challenging during a viral pandemic; the main concerns being the safety and protection of patients and health care providers (HCP). The aim of this study is to identify endoscopic practice patterns and outcomes of IBD and coronavirus disease 19 (COVID-19) with a worldwide survey of HCP. Methods: The 20-item survey questionnaire was sent to physician members of the American Society for Gastrointestinal Endoscopy Special Interest Group in Interventional IBD, Chinese IBD Society Endoscopy Interest Group, and the China Crohn's and Colitis Foundation. Results: A total of 141 respondents submitted valid responses. Nighty-five respondents (67.9\%) reported that at least $25 \%$ of their scheduled emergent endoscopic procedures were canceled or postponed during the pandemic. Fifty-six respondents (40.0\%) have performed emergent endoscopy during the pandemic. A few respondents $(9 / 140,6.4 \%)$ estimated that more than $25 \%$ of their patients had worsened disease due to delayed or canceled emergent endoscopy procedures. More than $80 \%$ of respondents believed that personal protective equipment (PPE) for the endoscopy team, room sterilization, and pre-procedure screening of patients for COVID-19 were necessary. Out of 140 respondents, $16(11.4 \%)$ reported that several of their patients had COVID-19. Eight clinicians (5.7\%) reported that they or their endoscopy colleagues developed work-related COVID-19. Conclusions: Cancellation of elective and emergent endoscopy in IBD care during the pandemic was common. Few respondents reported that their patients' disease conditions worsened due to the cancellation of the endoscopy procedure. Most respondents voiced the need for proper PPE during the procedure regardless of patients' COVID-19 status and screening the patients for COVID-19. (Intest Res 2021;19:332-340)

Key Words: COVID-19; Crohn disease; Endoscopy; Inflammatory bowel disease; Ulcerative colitis

Received April 25, 2020. Revised May 9, 2020. Accepted May 13, 2020. Correspondence to Bo Shen, Center for Inflammatory Bowel Disease, Columbia University Irving Medical Center, New York-Presbyterian Hospital, Herbert Irving Pavilion-Rm 843, 161 Ft Washington Ave, New York, NY 10032, USA. Tel: +1-212-305-5446, Fax: +1-212-305-0267, E-mail:

bs3270@colubmia.edu

*These authors contributed equally to this study.

\section{INTRODUCTION}

The current coronavirus disease 19 (COVID-19) pandemic has resulted in illness in more than 3.7 million persons worldwide as of May 8, 2020. The infection of severe acute respiratory syndrome coronavirus 2 (SARS-CoV-2) can lead to extra- 
pulmonary manifestations, including gastrointestinal (GI) symptoms. On the other hand, patients with underlying inflammatory bowel disease (IBD) may be susceptible to bacterial or viral infection either as a consequence of their underlying disease or immunosuppressive medications (ISM) as a treatment. In addition, patients with IBD often require endoscopic evaluation for the diagnosis, differential diagnosis, disease monitoring, assessment of treatment response, and therapeutic intervention. While most elective endoscopy has to be canceled or postponed for various reasons, emergent diagnostic or therapeutic endoscopy may be required during the pandemic. Interventional IBD, i.e. endoscopic management of complications of IBD or IBD surgery plays an important role in the provision of more effective treatment modalities than medical therapy and less invasive ways than surgical intervention. The main applications of interventional IBD include the following areas: (1) stricture therapy; (2) fistula and abscess therapy; (3) endoscopic management of colitis-associated neoplasia. ${ }^{1,2}$

COVID-19 from the highly contagious pathogen has imposed tremendous stress and burden on patients, health care providers (HCP), health care facilities, and society. It has been particularly challenging for IBD patients with the underlying disease, the use of ISM, malnutrition, complications (such as strictures, bleeding, and abscess), or their requirement of periodic diagnostic or therapeutic endoscopy. Additionally, there have been concerns about the protection and safety of patients and the endoscopy team during the procedure. Between February 12 and April 9, 2020, 315,531 COVID-19 cases were reported to the Centers for Disease Control and Prevention (CDC) using a standardized form, 49,370 (16\%) included data on whether the patient was an HCP in the United States. A total of 9,282 (19\%) persons with COVID-19 were identified as HCP. As of May 7, 2020, a total of 1,219,066 cases were reported to CDC. ${ }^{3}$ Endoscopists and endoscopy staff may be particularly vulnerable. ${ }^{4}$ There is a lack of evidence-based guidelines regarding optimal endoscopy practice during a viral pandemic. Current guidelines from professional societies are largely based on expert opinions. ${ }^{4}$ We urgently need realworld data. The current study was aimed to evaluate the practice pattern of IBD endoscopists in the management of their patients during the pandemic and to assess their concerns about personal protective equipment (PPE) and screening for COVID.

\section{METHODS}

\section{Participants}

Members of the American Society for Gastrointestinal Endoscopy (ASGE) Special Interest Group in Interventional IBD were surveyed with a structured 20-item anonymous questionnaire in both English and Chinese. In China, the questionnaires were distributed to physician members of the Chinese IBD Society Special Interest Group in IBD and the China Crohn's and Colitis Foundation. Of note, clinicians in Wuhan, the epicenter of COVID-19 in China were also enrolled. The survey was administered between April 12 and April 19, 2020.

The inclusion criteria for qualified HCP were: (1) general gastroenterologists with a practice including IBD; (2) IBD specialists doing diagnostic or therapeutic endoscopy for IBD patients; (3) colorectal surgeons specialized in IBD surgery doing diagnostic and/or therapeutic endoscopy for IBD patients and (4) advanced therapeutic endoscopist also treating IBD complications such as endoscopic balloon dilation of strictures.

The central institutional review board for the study was approved by the ethics committee of the 2nd Hospital of Zhejiang University (approval No. 2020001357).

\section{Survey Questionnaire}

The questionnaire was drafted and revised by core members of the research team (Y.C., C.N.B., F.A.F., R.P.K., and B.S.) based on a comprehensive review of the literature and personal expertise. The questionnaires mainly consisted of non-open-ended questions from the following categories: (1) HCP's practice setting and criteria of emergent versus elective endoscopy in IBD; (2) endoscopy practice patterns; and (3) risk and protective measures in the endoscopy suite and endoscopy team. The estimated time to complete the survey was from 5 to 7 minutes. The validity of answered questionnaires was performed by blinded investigators (Y.C., Q.Y., and B.S.). Data were sorted based on the category.

\section{Statistical Analysis}

Categorical variables were expressed as frequencies and percentages. Descriptive statistics were performed.

\section{RESULTS}

A total of 142 answered questionnaires were received with 141 deemed valid responses, 16 respondents from the United States and 125 from China. 


\section{Practice Setting and Volume and Criteria for Emergent and Elective Endoscopy in IBD}

More than 50\% were IBD clinicians or IBD endoscopists. Seventeen respondents (12.1\%) are the members of the ASGE Special Interest Group or the Global Interventional IBD Group. Of note, 7 respondents were from the City of Wuhan, the epicenter of the COVID-19 pandemic in China, of whom 6 were gastroenterologists with $>30 \%$ of IBD practice and 1 gastroenterologist with $<30 \%$ of IBD practice.

The weekly patient volume of IBD was significantly higher for the Chinese clinicians than the U.S. clinicians during the pandemic.

Fifty percent or more respondents felt that emergent endoscopy was applied to newly-onset acute severe colitis suspected of ulcerative colitis (UC) and Crohn's disease (CD) with clinically significant anastomosis bleeding, UC with endoscopically resectable polypoid lesion with high-grade dysplasia, and acute cholangitis in the setting or primary sclerosing cholangitis (Table 1).

\section{Practice Patterns during COVID-19}

Nighty-five respondents (67.9\%) reported that at least $25 \%$ of their scheduled emergent endoscopic procedures were canceled or postponed. All 7 respondents from the City of Wuhan reported that at least $25 \%$ of their patients' endoscopy was canceled or postponed for the concern about the risk of COVID-19. The main reasons for the cancellation or postponing of the scheduled IBD endoscopy are (1) patient decision; (2) endoscopist's concerns about the safety of patients and treatment team; and (3) local governmental or institutional restriction (Table 1).

Fifty-six respondents (40.0\%) performed emergent endoscopy during the pandemic. There were some agreements and disagreement on the criteria of emergent endoscopy in IBD patients, with posted scenarios. More than $50 \%$ of respondents believed that emergent endoscopy was applied to new-onset acute severe colitis, CD with anastomotic ulcer bleeding, concurrent UC and primary sclerosing cholangitis with acute cholangitis. In contrast, less than $50 \%$ of respondents believed that symptomatic CD-associated strictures in outpatients or inpa-

Table 1. Practice Setting and Volume and Criteria for Emergent and Elective Endoscopy in IBD

\begin{tabular}{|c|c|c|c|}
\hline Category & Choice & $\begin{array}{l}\text { Total number of } \\
\text { survey received }\end{array}$ & No. $(\%)$ \\
\hline \multirow[t]{8}{*}{ 1. Type of practice } & a. General gastroenterologist with a practice consisting of $>30 \%$ IBD & 141 & $51(36.2)$ \\
\hline & b. IBD specialist doing mainly diagnostic endoscopy for IBD patients & 141 & $15(10.6)$ \\
\hline & $\begin{array}{l}\text { c. IBD specialist routinely (more often than weekly) doing both diagnostic and } \\
\text { therapeutic endoscopies for IBD patients }\end{array}$ & 141 & $15(10.6)$ \\
\hline & $\begin{array}{l}\text { d. Colorectal surgeon specialized in IBD doing diagnostic }+/ \text { - therapeutic endoscopy } \\
\text { for IBD patients }\end{array}$ & 141 & $2(1.4)$ \\
\hline & e. Therapeutic endoscopist also treating IBD complications & 141 & $6(4.3)$ \\
\hline & $\begin{array}{l}\text { f. Pediatric gastroenterologist specialized in IBD doing diagnostic }+/ \text { - therapeutic } \\
\text { endoscopy of IBD }\end{array}$ & 141 & $3(2.1)$ \\
\hline & g. General gastroenterologist with a practice consisting of $<30 \%$ IBD & 141 & $48(34.0)$ \\
\hline & h. None of the above & 141 & $1(0.7)$ \\
\hline \multirow{7}{*}{$\begin{array}{l}\text { 2. Conditions you } \\
\text { believed to be } \\
\text { appropriate for } \\
\text { emergent endoscopy } \\
\text { during the pandemic }\end{array}$} & a. An outpatient with symptoms of obstruction and history of CD-related strictures & 140 & $60(32.9)$ \\
\hline & b. An inpatient with admitting diagnosis of bowel obstruction and CD-related strictures & 140 & $67(47.9)$ \\
\hline & c. Newly-onset acute severe colitis suspected of UC & 140 & $108(77.1)$ \\
\hline & d. Ileal pouch with symptomatic presacral abscess from chronic anastomotic leak & 140 & $56(40.0)$ \\
\hline & $\begin{array}{l}\text { e. } C D \text { patient in the emergency room with current and history of anastomotic bleeding } \\
\text { (hemoglobin from baseline } 9.5 \text { to } 7.5 \text { ) }\end{array}$ & 140 & $119(85.0)$ \\
\hline & $\begin{array}{l}\text { f. An UC patient with possible endoscopically resectable polypoid lesion with high- } \\
\text { grade dysplasia }\end{array}$ & 140 & $70(50.0)$ \\
\hline & $\begin{array}{l}\text { g. An outpatient with primary sclerosing cholangitis and } U C_{1} \text {, presents with acute } \\
\text { cholangitis requiring stent change }\end{array}$ & 140 & $118(84.3)$ \\
\hline
\end{tabular}

IBD, inflammatory bowel disease; CD, Crohn's disease; UC, ulcerative colitis. 
tients required emergent endoscopy. In reality, more than 50\% of responders have performed emergent endoscopy for precolectomy diagnosis for acute severe colitis. Precolectomy di- agnosis of severe acute colitis for the diagnosis IBD in some settings may be not be considered as a true indication for emergent endoscopy.

Table 2. Practice Pattern during COVID-19

\begin{tabular}{|c|c|c|c|}
\hline Category & Choice & $\begin{array}{l}\text { Total number of } \\
\text { survey received }\end{array}$ & No. (\%) \\
\hline \multirow{4}{*}{$\begin{array}{l}\text { 1. Average number of IBD patients seen } \\
\text { in the past week (face-to-face or } \\
\text { virtual visit) }\end{array}$} & a. $\leq 7$ & 140 & 53 (37.9) \\
\hline & b. $7-14$ & 140 & $37(26.4)$ \\
\hline & c. $25-30$ & 140 & $30(21.4)$ \\
\hline & d. $>30$ & 140 & $20(14.3)$ \\
\hline \multirow{5}{*}{$\begin{array}{l}\text { 2. Number of CD patients diagnosed with } \\
\text { COVID-19 }\end{array}$} & a. None & 140 & 132 (94.3) \\
\hline & b. 1-5 & 140 & 7 (5.0) \\
\hline & c. $6-10$ & 140 & $1(0.7)$ \\
\hline & d. $11-20$ & 140 & 0 \\
\hline & e. $>20$ & 140 & 0 \\
\hline \multirow{5}{*}{$\begin{array}{l}\text { 3. Number of UC patients diagnosed with } \\
\text { COVID-19 }\end{array}$} & a. None & 140 & 136 (97.1) \\
\hline & b. 1-5 & 140 & $3(2.1)$ \\
\hline & c. $6-10$ & 140 & $1(0.7)$ \\
\hline & d. $11-20$ & 140 & 0 \\
\hline & e. $>20$ & 140 & 0 \\
\hline \multirow{5}{*}{$\begin{array}{l}\text { 4. Number of ileal pouch patients } \\
\text { diagnosed with COVID-19 }\end{array}$} & a. None & 140 & 136 (97.1) \\
\hline & b. $1-5$ & 140 & $4(2.9)$ \\
\hline & c. $6-10$ & 140 & 0 \\
\hline & d. $11-20$ & 140 & 0 \\
\hline & e. $>20$ & 140 & 0 \\
\hline \multirow{5}{*}{$\begin{array}{l}\text { 5. Number of diagnostic or disease } \\
\text { monitoring endoscopy scheduled per } \\
\text { week since the outbreak }\end{array}$} & a. None & 140 & $42(30.0)$ \\
\hline & b. $1-5$ & 140 & 79 (56.4) \\
\hline & c. $6-10$ & 140 & $9(6.4)$ \\
\hline & d. $11-20$ & 140 & $7(5.0)$ \\
\hline & e. $>20$ & 140 & $3(2.1)$ \\
\hline \multirow{4}{*}{$\begin{array}{l}\text { 6. \% Scheduled IBD endoscopies were } \\
\text { postponed or canceled due to the } \\
\text { pandemic }\end{array}$} & a. $0-25$ & 139 & $44(31.7)$ \\
\hline & b. $26-50$ & 139 & $30(21.6)$ \\
\hline & c. $51-75$ & 139 & $16(11.5)$ \\
\hline & d. $>75$ & 139 & 49 (35.3) \\
\hline \multirow{5}{*}{$\begin{array}{l}\text { 7. Number of requested therapeutic } \\
\text { endoscopy per week during the } \\
\text { pandemic }\end{array}$} & a. None & 140 & $59(42.1)$ \\
\hline & b. 1-5 & 140 & 61 (43.6) \\
\hline & c. $6-10$ & 140 & $8(5.7)$ \\
\hline & d. $11-20$ & 140 & $5(3.6)$ \\
\hline & e. $>20$ & 140 & $7(5.0)$ \\
\hline \multirow{4}{*}{$\begin{array}{l}\text { 8. \% Requested therapeutic endoscopy } \\
\text { were postponed or canceled due to } \\
\text { the pandemic }\end{array}$} & a. 0-25 & 140 & 45 (32.1) \\
\hline & b. $26-50$ & 140 & $28(20.0)$ \\
\hline & c. $51-75$ & 140 & 19 (13.6) \\
\hline & d. $>75$ & 140 & 48 (34.3) \\
\hline
\end{tabular}


Table 2. Continued

\begin{tabular}{|c|c|c|c|}
\hline Category & Choice & $\begin{array}{l}\text { Total number of } \\
\text { survey received }\end{array}$ & No. $(\%)$ \\
\hline \multirow{5}{*}{$\begin{array}{l}\text { 9. Main reasons for the cancellation of } \\
\text { IBD endoscopy }\end{array}$} & a. Patient canceled the procedure & 140 & $96(68.6)$ \\
\hline & $\begin{array}{l}\text { b. You canceled the procedure for the concern of safety and your } \\
\text { team from the viral infection }\end{array}$ & 140 & $102(72.9)$ \\
\hline & $\begin{array}{l}\text { c. You canceled the procedure due to the patient's use } \\
\text { of immunosuppressives (systemic corticosteroids, } \\
\text { immunomodulators, or biologics) }\end{array}$ & 140 & $26(18.6)$ \\
\hline & d. You canceled the procedure due to the lack adequate PPE & 140 & $14(10.0)$ \\
\hline & $\begin{array}{l}\text { e. You canceled the procedure to obey the regulation from your } \\
\text { national, state, or local government or your institution }\end{array}$ & 140 & $115(82.1)$ \\
\hline \multirow{2}{*}{$\begin{array}{l}\text { 10. Ever emergent endoscopy for IBD } \\
\text { since the pandemic }\end{array}$} & a. Yes & 140 & $56(40.0)$ \\
\hline & b. No & 140 & $84(60.0)$ \\
\hline \multirow{4}{*}{$\begin{array}{l}\text { 11. Main indications(s) for the emergent } \\
\text { endoscopy }\end{array}$} & a. Precolectomy diagnosis for severe acute colitis suspected of IBD & 139 & $70(50.4)$ \\
\hline & b. Endoscopic therapy for the relief of obstructing stricture & 139 & $35(25.2)$ \\
\hline & c. Endoscopic treatment of abscess or anastomosis sinus & 139 & $18(13.0)$ \\
\hline & d. I have not performed any endoscopic procedures & 139 & $49(35.3)$ \\
\hline \multirow{5}{*}{$\begin{array}{l}\text { 12. \% IBD patients undergoing } \\
\text { endoscopy was tested positive for } \\
\text { COVID } 19\end{array}$} & a. $1-25$ & 138 & $30(21.7)$ \\
\hline & b. $26-50$ & 138 & 0 \\
\hline & c. $51-75$ & 138 & 0 \\
\hline & d. $>75$ & 138 & 0 \\
\hline & e. None & 138 & $108(77.7)$ \\
\hline \multirow{4}{*}{$\begin{array}{l}\text { 13. \% IBD patients who required } \\
\text { Emergent endoscopy but delayed, } \\
\text { had worsening disease }\end{array}$} & a. $0-25$ & 140 & 131 (93.6) \\
\hline & b. $26-50$ & 140 & $5(3.6)$ \\
\hline & c. $51-75$ & 140 & $2(1.4)$ \\
\hline & d. $>75$ & 140 & $2(1.4)$ \\
\hline \multirow{4}{*}{$\begin{array}{l}\text { 14. \% IBD patients scheduled for } \\
\text { elective endoscopy but delayed, had } \\
\text { worsening disease. }\end{array}$} & a. $0-25$ & 140 & 131 (93.6) \\
\hline & b. $26-50$ & 140 & $3(2.1)$ \\
\hline & c. $51-75$ & 140 & $4(2.9)$ \\
\hline & d. $>75$ & 140 & $2(1.4)$ \\
\hline
\end{tabular}

COVID-19, coronavirus disease 19; IBD, inflammatory bowel disease; CD, Crohn's disease; UC, ulcerative colitis; PPE, personal protective equipment.

A few respondents (9/140,6.4\%) estimated that more than $25 \%$ of their patients had a worsened disease due to delayed or canceled emergent endoscopy procedure (Table 1).

Out of 140 respondents, 16 (11.4\%) reported that some of their patients had COVID-19, including 8 (5.7\%) on CD patients, $4(2.9 \%)$ on UC patients, and $4(2.9 \%)$ on ileal pouch patients (Table 2). None of 7 respondents from the City of $\mathrm{Wu}-$ han reported that any of their IBD patients had COVID-19. Interestingly, only 1 Chinese respondent reported seeing IBD patients with COVID-19, and 15 U.S. clinicians reported some of their CD, UC, or ileal pouch patients had COVID-19 $(P<0.01)$.

\section{Risk and Protective Measures in the Endoscopy Suite and Endoscopy Team for COVID-19}

More than $80 \%$ of respondents, including all 7 respondents from the City of Wuhan believed that proper PPE for the endoscopy team, room sterilization, pre-procedure screening of patients for COVID-19 were necessary. Eighty-two respondents (58.6\%) recommended allowing the patient to wear PPE as well. For patients with or suspected of COVID-19, almost all respondents (138/140, 98.6\%) believed that HCP should wear proper PPE, consisting of filtering facepiece 2 (FFP2), FFP3, or N95 face masks, goggles or face shield, long-sleeved water-resistant gowns, and gloves. For patients without COVID-19, a vast majority of respondents ( $>80 \%$ ) recommended that HCP 
Table 3. Risk and Protective Measures in the Endoscopy Suite and Endoscopy Team for COVID-19

\begin{tabular}{|c|c|c|c|}
\hline Category & Choice & $\begin{array}{l}\text { Total number } \\
\text { of survey } \\
\text { received }\end{array}$ & No. (\%) \\
\hline \multirow{5}{*}{$\begin{array}{l}\text { 1. Important factors for the prevention of COVID-19 of } \\
\text { patients and endoscopy team }\end{array}$} & b. PPE for the treating team & 140 & 139 (99.3) \\
\hline & c. Room sterilization between procedures & 140 & $112(80.0)$ \\
\hline & e. Pre-procedure screening of the treating team & 140 & $74(52.9)$ \\
\hline & f. Not allowing trainees to be involved in the endoscopy & 140 & $27(19.3)$ \\
\hline & g. Others & 140 & $1(0.7)$ \\
\hline \multirow{4}{*}{$\begin{array}{l}\text { 2. Proper PPE when performing endoscopy in patients } \\
\text { with or suspected of COVID-19 or SARS-CoV-2 } \\
\text { infection }\end{array}$} & a. FFP respiratory class 2 or 3 (FFP2 or FFP3) or N95 type & 140 & $71(50.7)$ \\
\hline & b. Goggles or face shield & 140 & $71(50.7)$ \\
\hline & e. All above & 140 & $138(98.6)$ \\
\hline & f. None of above & 140 & 0 \\
\hline \multirow{4}{*}{$\begin{array}{l}\text { 3. Proper PPE endoscopist should wear when performing } \\
\text { endoscopy for patients without COVID-19 or SARS- } \\
\text { CoV-2 infection }\end{array}$} & a. FFP respiratory class 2 or 3 (FFP2 or FFP3) or N95 type & 140 & $116(82.9)$ \\
\hline & b. Goggles or face shield & 140 & $128(91.4)$ \\
\hline & c. Long-sleeved water-resistant gowns & 140 & $121(86.4)$ \\
\hline & d. Gloves & 140 & $133(95.0)$ \\
\hline \multirow{2}{*}{$\begin{array}{l}\text { 4. Any colleagues in the same department/division had } \\
\text { work-related COVID-19 or SARS-CoV-2 infection }\end{array}$} & a. Yes & 140 & $8(5.7)$ \\
\hline & b. No & 140 & 132 (94.3) \\
\hline
\end{tabular}

COVID-19, coronavirus disease 19; PPE, personal protective equipment; SARS-CoV-2, severe acute respiratory syndrome coronavirus 2; FFP, filtering face piece.

wore all PPE. Eight clinicians (5.7\%) reported that they or their endoscopy colleagues developed work-related COVID-19 (Table 3). Of the 8 clinicians, 2 (1.6\%) from China and 6 (37.6\%) from the United States reported that they or their colleagues contracted COVID-19 $(P<0.01)$.

\section{DISCUSSION}

The arrival of COVID-19 pandemic has changed the world in every aspect. Persons with IBD are susceptible to these changes regarding office visits, the use of ISM, endoscopy, hospitalization, and surgery. Endoscopy plays a key role in diagnosis, disease monitoring, and treatment. Alterations in IBD care during the pandemic include the scheduling, utilization, and execution of endoscopy. Two-thirds of respondents reported that at least $25 \%$ of their scheduled emergent endoscopic procedures were canceled or postponed. The main reasons for the cancellation or delay in endoscopy were patients' personal decisions and the endoscopists' concerns about the safety of patients and the treatment team. Among listed scenarios, such as new-onset acute severe colitis suspicious for IBD, CD patients with anastomotic ulcer bleeding, or acute cholangitis from primary sclerosing cholangitis. In addition, the majority of respondents voiced the mandate of suspending non-emergent endoscopy. The survey listed several common scenarios of emergent endoscopy with a good agreement among responders. The data showed that there was an overwhelming concern about PPE during endoscopy procedures.

Complications, such as stricture, fistula, abscess, and bleeding, are common in IBD patients, particularly in those with prior surgery. Most of these complications require periodic endoscopic therapy, such as balloon dilation and endoscopic stricturotomy. The endoscopic management of symptomatic patients during the pandemic has been challenging. Professional societies' guidelines have recommended assuring the highest level of endoscopy care as well as protection against COVID-19 for both patients and endoscopy suite personnel. ${ }^{3,5}$ The question is how can these measures be implemented. Elec- 
tive endoscopy has been postponed based on governmental or institutional mandates, patients' preferences, or endoscopist discretion, as shown in the current study. There are no setup criteria for emergent endoscopy. Results of our survey revealed some agreement and disagreement on the criteria of emergent endoscopy in IBD care. Practically the decision to perform the urgently needed endoscopy was at the discretion of treating endoscopists.

With regards to the performance of emergent endoscopy, the risk of delayed therapy with the subsequent possibility of worsening disease course versus the risk of COVID for both patients and HCPs in the endoscopy setting should be carefully balanced. Even some emergent endoscopic procedures have to be canceled. Fortunately, the majority of respondents (93.6\%) reported that less than $25 \%$ of patients with canceled emergent endoscopy experienced worsened disease. On the other hand, HCPs carry a higher risk for COVID-19. ${ }^{3}$ GI endoscopists and endoscopy personnel is at a particularly higher risk for acquisition of COVID-19., ${ }^{4,6}$ Sixteen respondents (11.4\%) reported that some of their patients had COVID-19, including 8 (5.7\%) on CD patients, 4 (2.9\%) on UC patients, and 4 (2.9\%) on ileal pouch patients. Eight respondents (5.71\%) reported that they or their endoscopy colleagues developed work-related COVID-19. If elective or some emergent IBD endoscopy can be cautiously postponed, it will reduce the risk of exposure of patients as well as HCPs to COVID-19.

Patients with COVID-19 can present with GI symptoms, such as bloating, nausea, abdominal pain, and diarrhea. Some of the patients may not have concurrent respiratory symptoms. ${ }^{7}$ These symptoms are not specific, which may mimic a flare of underlying IBD. The role of endoscopic evaluation for the distinction between COVID-19 with GI presentations and IBD disease flare is not clear. There are no published data on colonoscopic and histologic features in patients COVID-19 or SARS$\mathrm{CoV}-2$. Therefore, it is recommended that IBD patients with GI symptoms suspected of having SARS-CoV-2 or COVID-19 should initially have non-endoscopic evaluation. ${ }^{8}$ In this survey, $50 \%$ of the respondents performed emergent endoscopy for the precolectomy diagnosis of acute severe colitis suspected of IBD.

COVID-19 is primarily spread through droplet transmission. However, endoscopic procedures, for example, upper endoscopy, may cause aerosolization, and subsequent airborne transmission. Adequate personal protection and room setting are critical for the prevention of work-related COVID-19.19

There has been debate as to what the proper PPE should be for endoscopy personnel. ${ }^{5}$ The American Gastroenterological Association guidelines recommended the use of N95-type face masks for all HCPs performing upper GI or lower GI endoscopic procedures, regardless of patients' COVID-19 status. ${ }^{6}$ Recommended PPEs for GI endoscopy from various professional societies have been published. ${ }^{11}$ The results of this survey study showed that the overwhelming number of respondents recommended high-quality face masks (such as N95), goggles or face shield, long-sleeved water-resistant gowns, and gloves when performing endoscopy procedure in patients regardless COVID-19 status. Eighty-two responders (58.6\%) recommended letting the patient wear PPE as well, which could be applicable in IBD patients undergoing lower GI endoscopy. In addition, most respondents recommended room sterilization and pre-procedure screening of patients for COVID-19.

The findings of this study have several clinical implications. The cancellation of diagnostic or therapeutic endoscopy procedures for IBD is common for multiple reasons, including patients and endoscopists' concerns about the safety, personal protection, logistics (such as transportation and lodging during shelter-in-place), and the government's or institutional mandates. Most States' governments required cancellation or postponing of elective surgery or procedures. However, the definition of emergent endoscopy in IBD varies. The criteria of emergent IBD endoscopy has not been listed in professional societies' recommendations. ${ }^{11}$ Several scenarios of emergent endoscopy for IBD are listed in our recent consensus statement. ${ }^{12}$ Not all emergent endoscopies in IBD are therapeutic. For example, in this study, precolectomy endoscopy for the evaluation of acute severe colitis may be considered as an emergent procedure by some responders. Although the cancellation is common, it appears that disease progression due to the cancellation is uncommon. The group of respondents voiced concerns about PPE. In addition, the highly accurate point-of-care screening of patients for COVID-19 should become feasible in the United States, Canada, and Europe.

There are limitations to our study. This is not a controlled study. There might have been selection or recall bias. The respondents from the United States and China, with the majority being from the latter. The sample size may not be large enough to detect subtle changes and differences. The survey method using social media in WeChat in China would preclude the knowledge of the total number of clinicians who viewed the survey and who did not respond. The respondents represent a spectrum of IBD practice, from medical, endoscopic, to surgical, and from adult to pediatric service. The respondents from 
the epicenters of COVID-19 or from high-volume IBD centers may have a different experience than the others. Since the survey was obtained from clinicians, detailed clinical data of each patient were not available. With evolving pandemic of COVID-19 our knowledge of the virus and the management of COVID and underlying diseases are improving. The practice pattern of IBD care can be dynamic.

In conclusion, the cancellation of elective or emergent endoscopy in IBD care during the pandemic was common. There are agreement and disagreement in the criteria of emergent IBD endoscopy. Few respondents reported that their patients' disease conditions worsened due to the cancellation of the scheduled endoscopy procedure. Most respondents voiced the need for proper PPE during the procedure regardless of patients' COVID-19 status and recommended screening of the patient for the viral infection. The risks and benefits of performing diagnostic or therapeutic IBD endoscopy during the pandemic should be carefully balanced.

\section{ADDITIONAL INFORMATION}

\section{Funding Source}

The authors received no financial support for the research, authorship, and/or publication of this article.

\section{Conflict of Interest}

Farraye FA is a consultant for BMS, Braintree Labs, Gilead, GSK, Innovation Pharmaceuticals, Janssen, Pfizer, and Sebela. He sits on a DSMB for Lilly and Theravance. Bernstein CN has served on advisory boards for Abbvie Canada, Roche Canada, Janssen Canada, Takeda Canada, Pfizer Canada, consulted to Mylan Pharmaceuticals, has received educational grants from Abbvie Canada, Pfizer Canada, Takeda Canada, and Janssen Canada and has been on the speaker's panel for Janssen Canada, Abbvie Canada, Medtronic Canada, and Takeda Canada. $\mathrm{Wu} \mathrm{K}$ is a consultant and speaker for Xi'an Janssen, Takeda China, Abbvie, and CMS. Iacucci M is a consultant and speaker for Pentax, Abbvie, and Janssen and received a research grant from Pentax, Olympus, and Fujifilm. Shen B is a consultant and speaker for Abbvie, Janssen, and Takeda. The other authors declare that they have no conflicting interests.

\section{Author Contribution}

Conceptualization: Chen Y, Farraye FA, Bernstein CN, Iacucci M, Kiran RP, Shen B. Data curation: Chen Y, Navaneethan U, Wu H, Shen B. Formal analysis: Chen Y, Yu Q, Farraye FA, Zheng
JJ. Investigation: Chen Y, Yu Q, Farraye FA, Kochhar GS, Wu K, Zhong J, Schwartz DA, Zheng JJ, Shen B. Methodology: Chen Y, Yu Q, Farraye FA, Bernstein CN, Iacucci M, Shen B. Project administration: Chen Y, Kochhar GS, Navaneethan U, Wu H, Zheng JJ, Kiran RP, Shen B. Resources: Chen Y, Farraye FA, Wu K, Zhong J, Shen B. Supervision: Bernstein CN, Shen B. Validation: Yu Q, Wu K, Schwartz DA, Shen B. Visualization: Chen Y, Farraye FA, Kochhar GS, Shen B. Writing - original draft: Farraye FA, Bernstein CN, Shen B. Writing - review \& editing: Farraye FA, Kochhar GS, U Navaneethan, Bernstein CN, Wu K, Zhong J, Schwartz DA, Iacucci M, Kiran RP, Shen B. Approval of final manuscript: all authors.

\section{Others}

The authors are grateful to help and support of surveyed clinicians.

\section{ORCID}

Chen Y

Yu Q

Farraye FA

Kochhar GS

Bernstein CN

Navaneethan U

Wu K

Zhong J

Schwartz DA

Wu H

Zheng JJ

Iacucci M

Kiran RP

Shen B

https://orcid.org/0000-0003-3457-2560 https://orcid.org/0000-0002-9434-7114 https://orcid.org/0000-0001-6371-2441 https://orcid.org/0000-0002-0597-2760 https://orcid.org/0000-0001-8041-3574 https://orcid.org/0000-0002-7677-0349 https://orcid.org/0000-0002-0699-9666 https://orcid.org/0000-0003-4499-7263 https://orcid.org/0000-0002-7026-7099 https://orcid.org/0000-0002-0767-4177 https://orcid.org/0000-0001-9374-4639 https://orcid.org/0000-0003-2440-2592 https://orcid.org/0000-0003-2049-0003 https://orcid.org/0000-0002-7229-4840

\section{REFERENCES}

1. Shen B, Kochhar G, Navaneethan U, et al. Practical guidelines on endoscopic treatment for Crohn's disease strictures: a consensus statement from the Global Interventional Inflammatory Bowel Disease Group. Lancet Gastroenterol Hepatol 2020;5:393-405.

2. Shen B, Kochhar G, Navaneethan U, et al. Role of interventional inflammatory bowel disease in the era of biologic therapy: a position statement from the Global Interventional IBD Group. Gastrointest Endosc 2019;89:215-237.

3. Centers for Disease Control and Prevention. Characteristics of Health Care Personnel with COVID-19-United States, Febru- 
ary 12-April 9, 2020 [Internet]. c2020 [cited 2020 May 14]. https://www.cdc.gov/mmwr/volumes/69/wr/mm6915e6. htm?s_cid=mm6915e6_x.

4. Gralnek IM, Hassan C, Beilenhoff U, et al. ESGE and ESGENA position statement on gastrointestinal endoscopy and the COVID-19 pandemic. Endoscopy 2020;52:483-490.

5. Sultan S, Lim JK, Altayar O, et al. AGA Institute rapid recommendations for gastrointestinal procedures during the COVID-19 pandemic. Gastroenterology 2020;159:739-758.

6. Repici A, Maselli R, Colombo M, et al. Coronavirus (COVID-19) outbreak: what the department of endoscopy should know. Gastrointest Endosc 2020;92:192-197.

7. Li LY, Wu W, Chen S, et al. Digestive system involvement of novel coronavirus infection: prevention and control infection from a gastroenterology perspective. J Dig Dis 2020;21:199204.

8. Rubin DT, Abreu MT, Rai V, Siegel CA; International Organization for the Study of Inflammatory Bowel Disease. Manage- ment of patients with Crohn's disease and ulcerative colitis during the COVID-19 pandemic: results of an international meeting. Gastroenterology 2020;159:6-13.

9. Soetikno R, Teoh AY, Kaltenbach T, et al. Considerations in performing endoscopy during the COVID-19 pandemic. Gastrointest Endosc 2020;92:176-183.

10. Lui RN, Wong SH, Sánchez-Luna SA, et al. Overview of guidance for endoscopy during the coronavirus disease 2019 pandemic. J Gastroenterol Hepatol 2020;35:749-759.

11. Castro Filho EC, Castro R, Fernandes FF, Pereira G, Perazzo H. Gastrointestinal endoscopy during the COVID-19 pandemic: an updated review of guidelines and statements from international and national societies. Gastrointest Endosc 2020;92:440445.

12. Iacucci M, Cannatelli R, Labarile N, et al. Endoscopy in inflammatory bowel diseases during the COVID-19 pandemic and post-pandemic period. Lancet Gastroenterol Hepatol 2020; 5:598-606. 